

\title{
Compressive performance and deformation mechanism of the dynamic gas injection aluminum foams
}

Ningzhen Wang, Eric Maire, Xiang Chen, Jérôme Adrien, Yanxiang Li, Yasin Amani, Lei Hu, Ying Cheng

\section{- To cite this version:}

Ningzhen Wang, Eric Maire, Xiang Chen, Jérôme Adrien, Yanxiang Li, et al.. Compressive performance and deformation mechanism of the dynamic gas injection aluminum foams. Materials Characterization, 2019, 147, pp.11-20. 10.1016/j.matchar.2018.10.013 . hal-01896700

\author{
HAL Id: hal-01896700 \\ https://hal.science/hal-01896700
}

Submitted on 16 Oct 2018

HAL is a multi-disciplinary open access archive for the deposit and dissemination of scientific research documents, whether they are published or not. The documents may come from teaching and research institutions in France or abroad, or from public or private research centers.
L'archive ouverte pluridisciplinaire HAL, est destinée au dépôt et à la diffusion de documents scientifiques de niveau recherche, publiés ou non, émanant des établissements d'enseignement et de recherche français ou étrangers, des laboratoires publics ou privés. 


\title{
Compressive performance and deformation mechanism of the
}

\section{dynamic gas injection aluminum foams}

\author{
Ningzhen Wang ${ }^{1}$, Eric Maire², Xiang Chen ${ }^{1,3}$, , Jérôme Adrien², Yanxiang Li ${ }^{1,3}$, Yasin Amani², \\ Lei $\mathrm{Hu}^{1}$, Ying Cheng ${ }^{1}$ \\ ${ }^{1}$ Department of Materials Engineering, School of Materials Science and Engineering, Tsinghua University, Beijing, 100084, China \\ ${ }^{2}$ INSA de Lyon, MATEIS CNRS UMR5510, Université de Lyon, 69621 Villeurbanne, France \\ ${ }^{3}$ Key Laboratory for Advanced Materials Processing Technology (MOE), Tsinghua University, Beijing, 100084, China \\ *Corresponding author: Tel: +86 10 62786355, E-mail: xchen@ tsinghua.edu.cn
}

Abstract: The dynamic gas injection method with high-speed horizontal oscillation could reduce the cell size and improve the cell quality of aluminum foams, so it is of interest to study the compressive performance and deformation mechanism of the foams produced with this process. In-situ compression in X-ray tomography was used for this research. Results have shown that the plateau stresses of bulk aluminum foams prepared by the dynamic gas injection method are in the range of $0.3 \sim 11 \mathrm{MPa}$. When the cell size is reduced to around $1 \mathrm{~mm}$, the plateau stress could reach $22 \mathrm{MPa}$. In addition, the brittle deformation characteristics of aluminum foams in the quasi-static compression process are obvious. The dynamic gas injection method could greatly improve the mechanical properties of aluminum foams, and aluminum foams prepared by this method have a better compressive performance compared to that prepared by static method even at the same relative density. The uniformity of the cell size and sphericity also affects the mechanical properties. The result of in-situ compression shows that there are two main failure modes for cell walls of aluminum foams: the fracture after buckles of the cell walls and the direct fracture of the cell walls. The aluminum foams prepared by the dynamic gas injection method could have a wide application prospect due to its superior compressive performance.

Key words: aluminum foam, gas injection method, mechanical properties, in-situ compression, deformation mechanism

\section{Introduction}

Closed-cell aluminum foams are a kind of foam structure with closed cellular pores inside the aluminum or aluminum alloy [1]. They have attracted some attention due to their light weight, good energy absorption, noise reduction and electromagnetic shielding performances [2]. There are three different zones in the stress-strain compressive curves of aluminum foams: linear elastic region, stress plateau region (plastic deforming) and densification region [3]. The area under the stress-strain curve corresponds to the energy that aluminum foams can absorb. Because the stress remains almost constant with increasing strain in the plateau stage, aluminum foams can absorb a lot of energy in the deformation process [4-7]. In the case of closed-cell aluminum foams, the entrapped gas inside the cells also plays an important role in the dynamic compression, which extends their application in impact and explosion-proof domains [8, 9]. Good energy absorption properties of closed-cell aluminum foams make them have wide applications in automotive, aerospace and military industries. [2, 10]. Mechanical properties of aluminum foams are influenced by their relative density $[9,11]$, matrix $[12,13]$, the microstructure of the cell walls [14], cell shapes [15] and cell size [16]. These factors are largely related to the preparation methods of closed-cell aluminum foams [17-20]. 
Gas injection is one of the main methods to produce closed-cell aluminum foams [1]. The process involves injecting gas directly into the molten aluminum or aluminum alloy containing ceramic particles [21, 22]. Compared to the widely used melt foaming method (Alporas) in the industry [1], gas injection method has the advantage of permitting continuous production. [18]. An aluminum foam prepared by gas injection method has some key microstructural features, such as an oxide film in the cell walls caused by the oxidizing gas [23], the A356 matrix which is usually used [24], and ceramic particles which are necessary for the bubbles stability [25]. These features can affect the cell structures and cell wall microstructures of aluminum foams, and certainly affect the compressive performance [14]. Therefore, it is necessary to study the compressive performance of aluminum foams prepared by gas injection method.

Static gas injection method means the gas injection needle was in static condition during the preparation process for uniform cells [7, 11]. In order to reduce the size of bubbles and then improve the mechanical properties of gas injection aluminum foams, some dynamic methods were applied in the gas injector, such as the rotating or reciprocating of the gas injector developed by Cymat [22, 26], ultrasonic oscillation used by Aluhab [27], mechanical vibration generated by a stepper motor [28] and the high-speed horizontal oscillation [29]. The mechanical properties of some gas injection aluminum foams have been reported, such as the static gas injection aluminum foam [11, 30], Aluhab prepared by ultrasonic oscillation method [31] and aluminum foam prepared by rotating gas injector [32]. There have also been some research about Cymat aluminum foams, but their cell size uniformity was not satisfactory [33,34]. Dynamic gas injection method assisted with high-speed horizontal oscillation could significantly reduce the cell size and improve the cell quality [29], so the compressive performance and deformation mechanism of this dynamic gas injection aluminum foam deserve to be studied in detail.

The energy absorption performance of the aluminum foam is related to the failure modes of cells [35]. The modes usually contain the formation of plastic hinges, tearing, fracture and buckling of cell membranes [15, 35]. At present, methods for characterizing cell deformation mainly include photographs of the deformation process [30], scanning electron microscope (SEM) [36], and X-ray tomography [33, 37, 38]. Cell deformation is difficult to be observed clearly by the pictures in compression due to the resolution limit [30]. The effective test zone of SEM method is usually small [36]. More importantly, the two methods mentioned above could only show the deformation of cells in the outer surface of the sample. In fact, the deformation of each cell can be affected by the surrounding cells, and the deformation of cells in outer surface is not that representative due to fewer constraints compared to the internal cells. Some researchers used finite element simulations based on the model from X-ray tomography to study the cell deformation, but it is hard to consider all factors in the simulation of the compressive process [33, 37]. C. Petit et al. [38] used the in-situ test coupled with X-ray tomography in the study of open-cell aluminum foam, and showed that this can be a proper way to characterize the cell deformation. The deformation process of the internal foam structure can be obtained through X-ray tomography during compression test which allows one to study the cell deformation mechanism quantitatively.

In this paper, the compressive performance and deformation characteristics of aluminum foams prepared by dynamic gas injection method assisted with high-speed horizontal oscillation was studied by standard compressive tests, and it was compared with the mechanical properties of aluminum foams prepared by static gas injection method. The cell deformation mechanism of the 
dynamic gas injection aluminum foams was studied by in-situ compressive tests assisted with X-ray tomography.

\section{Experimental Procedures}

\subsection{Standard compressive test of aluminum foams}

In the preparation of aluminum foams used for the compressive test, first the commercial A356 alloy was melted as $700{ }^{\circ} \mathrm{C}$, and $\mathrm{Al}_{2} \mathrm{O}_{3}$ particles with the size of $10 \mu \mathrm{m}$ and the fraction of 10 vol.\% were added into the aluminum alloy melt assisted with mechanical stirring. Then, the compressed air was injected into the melt by a gas injection system, bubbles could detach from the gas injection needle and rise to the melt surface. Finally, the solidified foam could be collected from the surface of the melt. In order to reduce the cell size of aluminum foams, a high-speed horizontal oscillation was applied into the gas injection needle, which has been described in detail in the literature [29], and the dynamic gas injection method mentioned below all refer to this method.

Ten bulk foam samples with porosity between $75 \%$ and $95 \%$ prepared by the dynamic gas injection method were chosen for compressive tests, their porosity distribution is shown in Table 1. In order to facilitate the analysis, the relative density was also used as a variable during the study of mechanical properties of aluminum foams, and the relationship between porosity and relative density is shown in Eq. 1. The cell diameter of the foam samples for compression is in the range of 2-12 mm. Foam samples were cut into a cylindrical or rectangular shape. In order to ensure that every foam has at least 10 cells in each direction, the sample size was mainly determined by the cell size of the aluminum foam. In addition, several aluminum foams prepared by static gas injection method were also compressed for comparison, but the data on the compressive performance of static gas injection aluminum foams mainly comes from literature [11].

Table 1 Porosities of aluminum foams used for compressive test

\begin{tabular}{|c|c|c|c|c|c|c|c|c|c|c|}
\hline Foam Number & 1 & 2 & 3 & 4 & 5 & 6 & 7 & 8 & 9 & 10 \\
\hline Porosity (\%) & 75.9 & 77.8 & 81.0 & 82.1 & 84.3 & 85.3 & 88.8 & 91.7 & 91.9 & 95.0 \\
\hline
\end{tabular}

where $P_{\mathrm{d}}$ is the measured porosity of aluminum foam. $\rho^{*}$ is the overall density of the aluminum foam, which is calculated from the weight and volume of the foam sample. $\rho_{\mathrm{s}}$ is the density of the matrix material (equal to $2.685 \mathrm{~g} / \mathrm{cm}^{3}$ ).

Compressive tests were conducted on a WDW-200E electronic universal testing machine, and the loading rate was $4 \mathrm{~mm} / \mathrm{min}$. The strain rate of every foam sample was in quasi-static compressive condition at this loading rate. The load-displacement data during the compression could be obtained after the test, and then the nominal stress $\sigma$ and nominal strain $\varepsilon$ can be calculated by Eqs. (2) and (3), respectively.

$$
\begin{gathered}
\sigma=\frac{F}{A} \\
\varepsilon=\frac{\Delta h}{h_{0}}
\end{gathered}
$$

where $F$ is the load obtained from the compression experiment. $A$ is the loading area of the foam sample. $\Delta h$ is the deformation of the sample along the compression direction, namely the 
displacement obtained from the experiment. $h_{0}$ is the original height of the sample.

A schematic stress-strain curve of aluminum foam during compression is shown in Fig. 1. It can be divided into three stages: elastic deformation stage (I), stress plateau stage (II) and densification stage (III). The energy absorption capacity of an aluminum foam is usually characterized by the densification strain energy $W_{\mathrm{D}}$, and its compressive performance is usually represented by the plateau stress $\sigma_{\mathrm{P}} . \varepsilon_{0}$ is the strain corresponding to the first peak stress in the curve. $\varepsilon_{\mathrm{D}}$ is the densification stain, namely the strain at the end of the plateau region. Densification strains of most samples in this paper were determined by the extreme point of the energy absorption efficiency-strain curve, and the detailed calculation process is detailed in [39]. For the aluminum foam with large cells (usually larger than $10 \mathrm{~mm}$ ), the severe collapse of cell walls will lead to large fluctuation in the stress-strain curve, and then the densification strain determined by the above calculation method will not be accurate. Therefore, densification strains of aluminum foams with large cells were re-determined manually. Then, the densification strain energy and plateau stress of aluminum foams could be calculated by Eqs. (4) and (5), respectively.

$$
\begin{gathered}
W_{\mathrm{D}}=\int_{0}^{\varepsilon_{\mathrm{D}}} \sigma(\varepsilon) \mathrm{d} \varepsilon \\
\sigma_{\mathrm{P}}=\frac{\int_{\varepsilon_{0}}^{\varepsilon_{\mathrm{D}}} \sigma(\varepsilon) \mathrm{d} \varepsilon}{\varepsilon_{\mathrm{D}}-\varepsilon_{0}}
\end{gathered}
$$

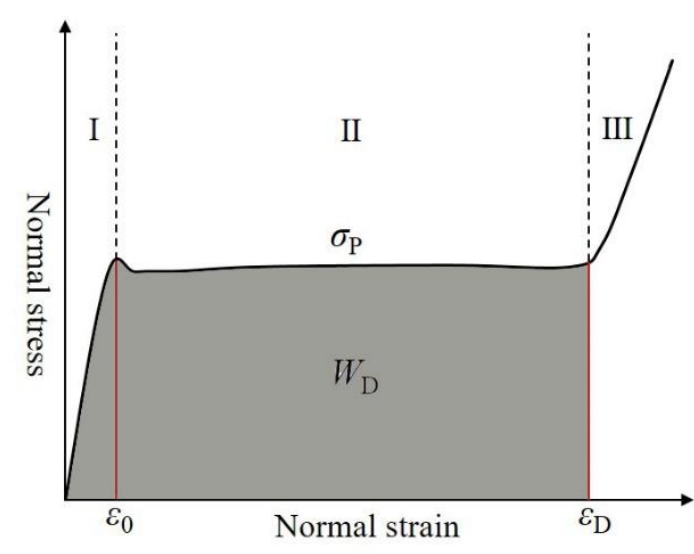

Fig. 1. A schematic compressive stress-strain curve of an aluminum foam

\subsection{X-ray tomographic characterization and in-situ compressive test}

In order to study the effect of cell parameters on the compressive properties of aluminum foams, some foam samples were scanned by X-ray tomography before being compressed. A laboratory X-ray tomography equipment described in [40] was used in this study. The resolution during the scanning was $50 \mu \mathrm{m}$ per voxel. Fiji software was used to process the reconstructed 3D images. The pore morphology of the foam sample could be obtained by a home-made plugin called "Param 3D" from the binarized 3D image. In order to avoid the influence of cell connection after binarization, cells were splitted by using "3D watershed split" plugin in Fiji first, and then the morphological parameters of every splitted cell could be obtained by "Param 3D" plugin. The detailed cell characterization process was described in [41].

The X-ray tomography equipment was also used for the in-situ compressive test. One aluminum foam sample with uniform small cells was placed in an aluminum tube with an inner diameter of $15 \mathrm{~mm}$ and a wall thickness of $1 \mathrm{~mm}$. This tube is almost transparent to the X-ray. A 
force sensor was attached to the upper surface of the sample through a grip in the aluminum tube, and the tube containing the sample was connected to a motor. Then, the assembled device was placed on the rotating stage of the X-ray equipment. The detailed description of the compression rig is given in $[38,40]$. Due to the limitation of the aluminum tube size, the dimension of the foam sample for in-situ compression are $8 \mathrm{~mm}$ in length, $8 \mathrm{~mm}$ in width and $10 \mathrm{~mm}$ in height. The average cell diameter of the sample is about $1 \mathrm{~mm}$, so there are enough cells along the compression direction. The loading rate of the compression was $0.005 \mathrm{~mm} / \mathrm{s}$, so the in-situ compression is in the quasi-static condition. The sample was scanned 19 times throughout the compression process, and the resolution of each scan was $8 \mu \mathrm{m}$ per voxel. The compressive process was stopped during the X-ray scanning, which takes about half an hour for each scan. In order to observe the initial deformation of cells more clearly, the interval of the first $12 \mathrm{X}$-ray tomography scans was $60 \mathrm{~s}$, namely the sample was compressed $0.3 \mathrm{~mm}$ between two scans. The interval of the subsequent 7 scans was $100 \mathrm{~s}$, namely the sample was compressed $0.5 \mathrm{~mm}$ between two scans. After the whole compression process, the load-displacement data during X-ray scanning could be removed according to the load values. Then, the continuous load-displacement curve could be obtained.

\section{Results and discussion}

\subsection{Compressive performance of dynamic gas injection aluminum foams}

Fig. 2 shows quasi-static compression stress-strain curves of aluminum foams in Table 1, and the bulk aluminum foams were all prepared by the dynamic gas injection method with high-speed horizontal oscillation. The three-stage characteristics are observed in stress-strain curves of all aluminum foams especially fluctuations in the stress plateau stage. It can also be seen that the level of the plateau stress increases with decreasing porosity. The plateau stress is usually used to represent the mechanical properties of aluminum foams, and it can be increased from $0.3 \mathrm{MPa}$ to $11 \mathrm{MPa}$ when the porosity is reduced from $95 \%$ to $75 \%$. The dot-dash line in Fig. 2 shows that the densification strain of aluminum foams roughly decreases with decreasing porosity. It is mainly because the reduced porosity leads to the increased volume fraction of the solid phase, and this causes the earlier densification stage during the compression test.

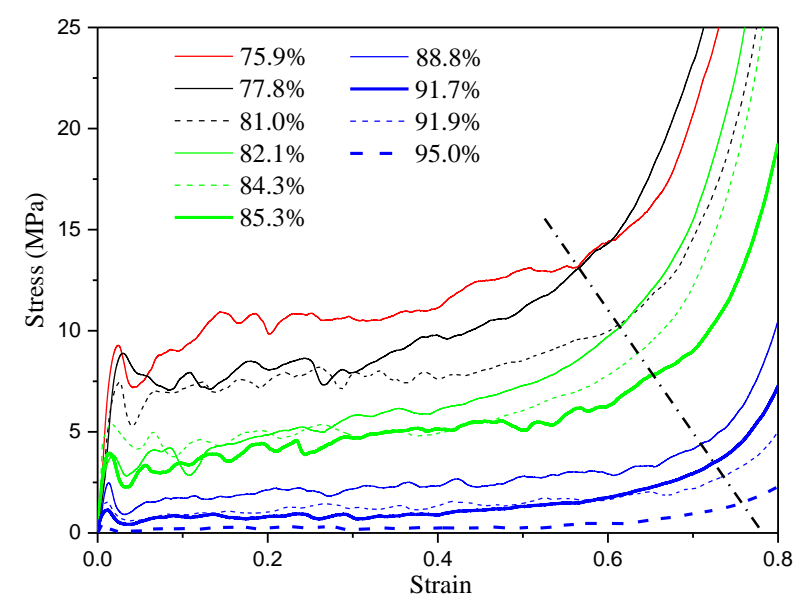

Fig. 2. Stress-strain curves of aluminum foams prepared by the dynamic gas injection method 
Fig. 3(a) shows energy absorption-strain curves of aluminum foams with different porosities before densification stage. It can be seen that the energy absorbed by aluminum foams increases with increasing strain. The energy absorption also increases with decreasing porosity under the same strain, which is consistent with the variation of the plateau stress with porosity. Fig. 3(b) shows the variation of densification strain energy with relative density of aluminum foams. Although the densification strain decreases with the increase of relative density (i.e. the decrease of porosity), the densification strain energy increases with increasing relative density, which is mainly due to the increased plateau stress. Therefore, the aluminum foam with high relative density should be used when huge amount of energy needs to be absorbed.
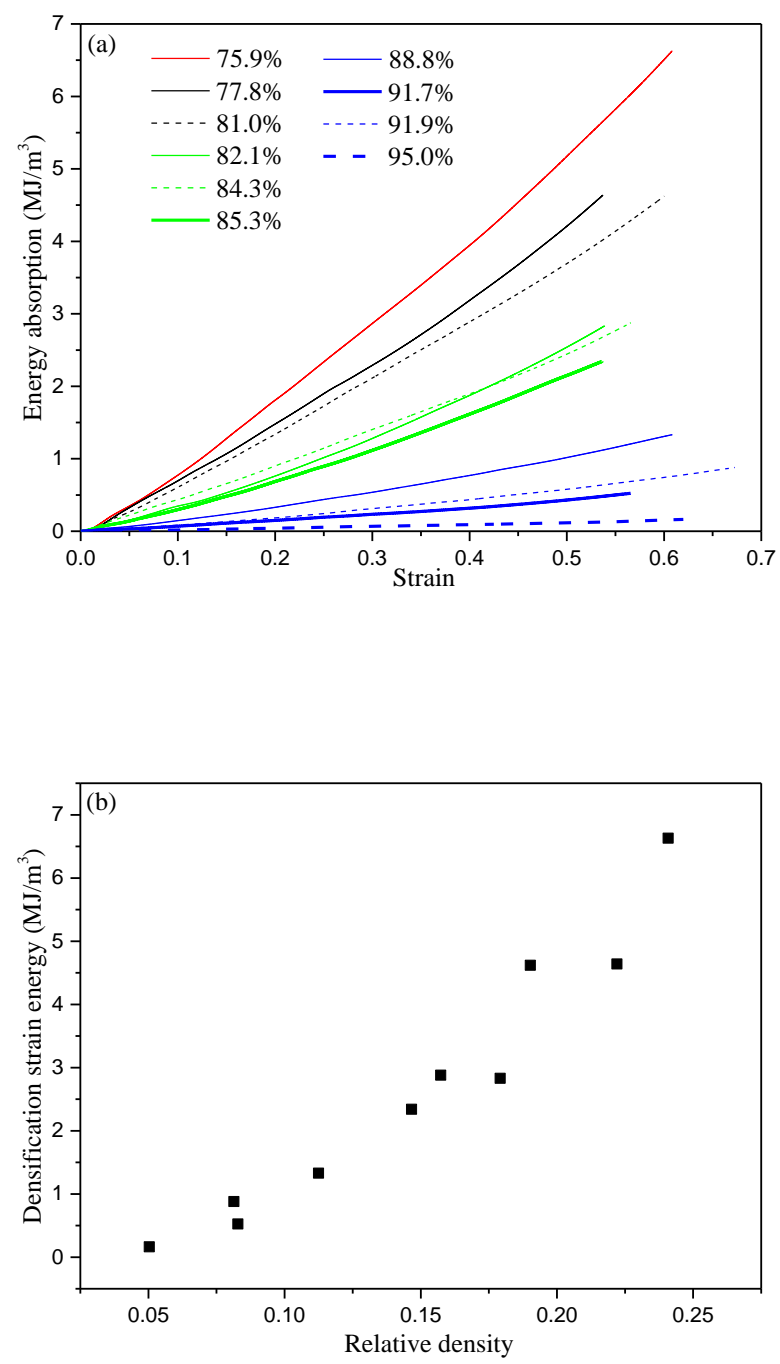

Fig. 3. (a) Energy absorption-strain curves of aluminum foams with different porosities. (b) Variation of densification strain energy with relative density of aluminum foams

Fig. 4 shows the deformation morphologies of an aluminum foam with the porosity of $85 \%$ during compression as observed by optical macrography from the outside of the sample. Fig. 4(b), (c) and (d) show the layer by layer collapse of cells in the stress plateau stage, and the strain localization. There are some fluctuations in the plateau stage of stress-strain curves of gas 
injection aluminum foams, as shown in Fig. 2. The fluctuation is the sudden drop of stress caused by the sudden collapse of a certain layer of cells during compression process, which is ultimately due to the brittleness of the aluminum foam. Fig. 4(e) shows that when the compression proceeds around the densification strain, several wide cracks along the axial direction appear in the outer layer of the specimen, which are certainly caused by the brittleness of the foam. When almost all cells are compacted, some cell walls in the outer layer peel off under the influence of these cracks, as shown in Fig. 4(f).

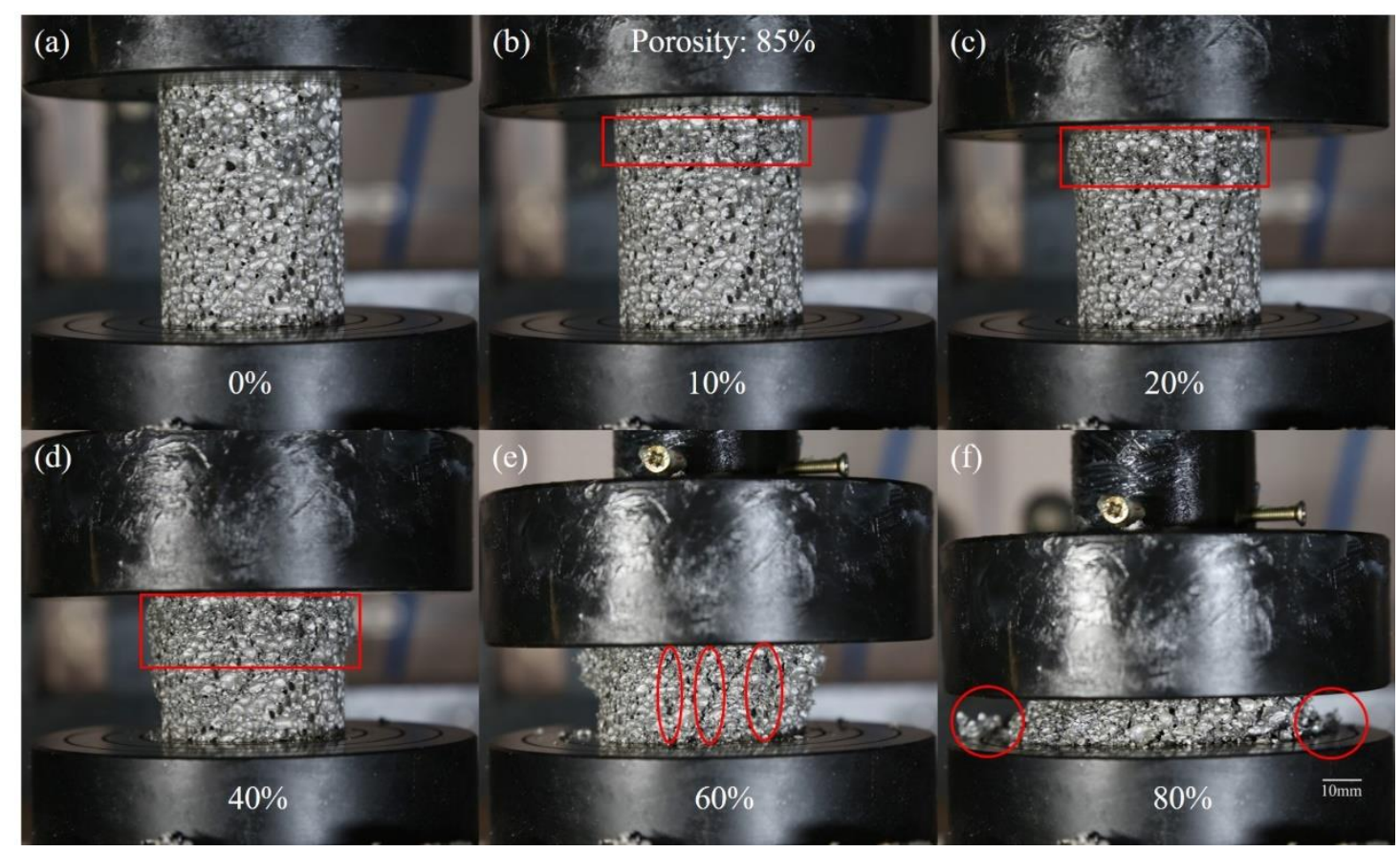

Fig. 4. Deformation morphologies of an aluminum foam during compression

Nominal strains from (a) to (f) are $0 \%, 10 \%, 20 \%, 40 \%, 60 \%, 80 \%$

According to the previous analysis, the brittle deformation characteristics of aluminum foams prepared by the dynamic gas injection method is obvious. The brittleness is mainly caused by three factors. (1) Due to the addition of ceramic particles $\left(\mathrm{Al}_{2} \mathrm{O}_{3}\right)$ during the preparation process, there are many ceramic particles in the cell walls of aluminum foam [23, 29]. There are also oxide films covering the cells walls due to the effect of oxidizing gas source (air) [23]. These brittle components will cause the brittleness of cell walls. (2) A356 aluminum alloy has been used as the matrix in the preparation, and the coarse eutectic silicon phase in the alloy contributes to the brittleness of the foam [29, 42]. (3) The thickness difference between normal cell wall and Plateau border is relatively bigger in the aluminum foams prepared by gas injection method [41]. Thinner normal cell wall makes the cell easier to collapse during the compression. These three reasons cause the brittleness of gas injection aluminum foams, and then some fluctuations appear in the stress-strain curve.

\subsection{Effects of preparation methods and cell structures on the compressive performance of gas injection aluminum foams}

Fig. 5 shows variation of plateau stress with relative density of aluminum foams prepared by the dynamic gas injection method (GIdyn) and static gas injection method (GIsta) in compression, and some compressive results of aluminum foams prepared by static method have been published in [11]. The axes are scaled logarithmically in Fig. 5 for the better comparison. The application of 
high-speed horizontal oscillation method could reduce the cell size of aluminum foams, and significantly increase the relative density accordingly, then the mechanical properties of aluminum foams could be increased, as shown in Fig. 5. More importantly, the aluminum foam prepared by dynamic gas injection method has a higher plateau stress than that prepared by static method even at the same relative density. According to Gibson and Ashby's theory [3], the relation between the plateau stress and relative density of aluminum foam could be fitted with a power function [43, 44]. Eqs. (6) and (7) show the plateau stress-relative density fitting results of aluminum foams prepared by dynamic and static gas injection methods, respectively. It could be seen from Fig. 5 that two points with low relative density for static method do not fit well with the line. It is because cell size is usually large and uneven under low relative density condition, and more internal defects will exist on the cell walls, then the internal defects will lead to the instability of mechanical performance.

$$
\begin{gathered}
\sigma_{\mathrm{P}}=184\left(\frac{\rho^{*}}{\rho_{\mathrm{s}}}\right)^{1.98} \\
\sigma_{\mathrm{P}}=155\left(\frac{\rho^{*}}{\rho_{\mathrm{s}}}\right)^{2.14}
\end{gathered}
$$

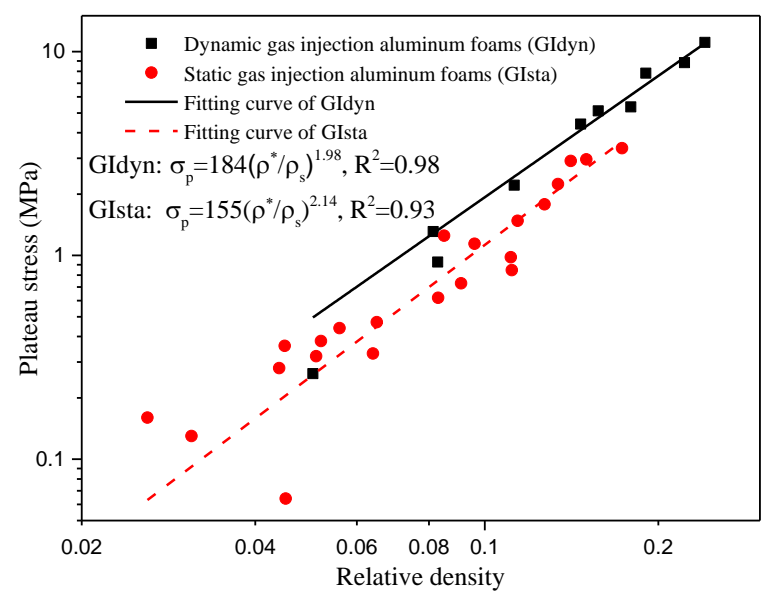

Fig. 5. Variation of plateau stress with relative density of aluminum foams prepared by different gas injection methods

Plateau stresses of different gas injection aluminum foams both increase with the increase of relative density. According to the fitting lines in Fig. 5, the intercept of the fitting line of GIdyn is bigger that of GIsta. Moreover, since the relative density of the aluminum foam is always less than 1, the smaller slope of the fitting line of GIdyn would also cause higher plateau stress. Therefore, the compressive performance of aluminum foams prepared the dynamic method would always higher than that prepared by static method at the same relative density. The movement state of the gas injector is nearly the only difference between the two methods in Fig. 5. It could cause different cell structures and ceramic particles distributions in cell walls, and then lead to different properties of the two kinds of aluminum foams. In terms of cell structure, aluminum foams with smaller cell size could be obtained by dynamic method at the same relative density condition, 
which is conductive to higher mechanical performance [30]. In terms of performance of cell walls, the rising path of bubbles in the dynamic gas injection system would be longer compared to that in static method, then more ceramic particles probably be absorbed in the cells walls, so higher mechanical performance would be obtained. In summary, due to the better cell wall performance and smaller cell size, the aluminum foam prepared by dynamic gas injection method has better mechanical properties compared to that prepared by static method even at the same relative density.

In order to further study the influencing factors of compressive performance of aluminum foam, three samples with similar porosity (similar relative density) were selected, two were prepared by dynamic gas injection method with high-speed horizontal oscillation and one was prepared by the static method. The X-ray tomography was used to characterize the cell structure of these three samples. Table 2 shows the cell parameters of three foams, and they are named according to their preparation method. $P_{\mathrm{d}}$ is the measured porosity obtained by relative density in Eq. (1), $P_{\mathrm{CT}}$ is the calculated porosity from $3 \mathrm{D}$ tomography images, and $\bar{d}$ is the average diameter of cells calculated by Fiji software in Table 2. It could be seen that $P_{\mathrm{d}}$ and $P_{\mathrm{CT}}$ for the three samples are both around $85 \%$, their difference lays mainly in the cell size.

Quasi-static compression stress-strain curves of the three aluminum foams are shown in Fig. 6. The fluctuations in the plateau stage of the curves are obvious as expected. The plateau stresses of Dyn-1 Dyn-2 and Sta-1 are 5.1 MPa, 4.4 MPa and 2.9 MPa, as shown in Table 2. The Sta-1 aluminum foam has the lowest plateau stress and the biggest average cell size. However, the average cell size of Dyn-1 is bigger than that of Dyn-2, but Dyn-1 has the highest plateau stress. Therefore, when the porosity is similar, the mechanical performance of aluminum foams is not completely determined by the average cell size.

Table 2 Cell parameters and compressive performance of three aluminum foams with similar porosity

\begin{tabular}{cclcccc}
\hline Number & Preparation method & Name & $P_{\mathrm{d}}(\%)$ & $P_{\text {СT }}(\%)$ & $\bar{d}(\mathrm{~mm})$ & $\sigma_{\mathrm{P}}(\mathrm{MPa})$ \\
\hline 1 & Dynamic gas injection & Dyn-1 & 84.3 & 85.5 & 3.45 & 5.1 \\
2 & Dynamic gas injection & Dyn-2 & 85.3 & 84.6 & 2.79 & 4.4 \\
3 & Static gas injection & Sta-1 & 85.9 & 85.2 & 4.55 & 2.9 \\
\hline
\end{tabular}

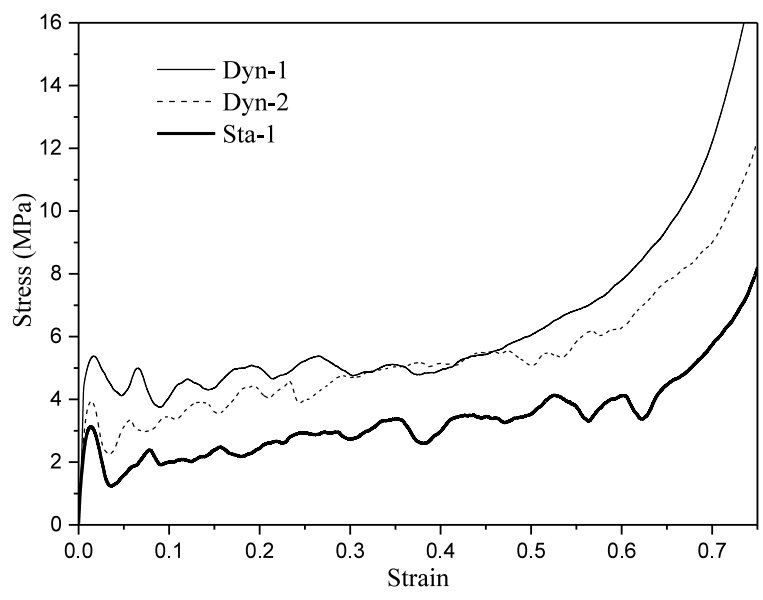

Fig. 6. Stress-strain curves of three gas injection aluminum foams with the porosity of $85 \%$ 
Fig. 7 shows distributions of equivalent diameter and sphericity of cells in the three aluminum foams illustrated in Fig. 6 and Table 2. The result was based on each individual 3D cell data obtained by Fiji software. Color of the scatter represents the number of cells with corresponding diameter and sphericity in the sample. When colors in the upper part of the color bar are mainly gathered in a certain position, it means the cell size and sphericity distributions of the foam sample are relatively uniform. Actually, the cell characterization results of the three samples have been mentioned in [41], which are listed here for further comparison. It can be seen that most cells in Dyn-1 sample have a diameter of about $4 \mathrm{~mm}$, and the sphericity is concentrated around 0.8. While the diameter of most cells in Dyn-2 sample is between $1.5 \sim 4.5 \mathrm{~mm}$, and the sphericity is mainly distributed in the range between $0.6 \sim 0.8$. Therefore, the more uniform cell size and sphericity distributions of Dyn-1 are the main reason for its higher plateau stress. However, Sta-1 sample also shows a uniform cell diameter and sphericity distributions, but its plateau stress is still lower than Dyn-1. This is related to its cell wall performance and larger average cell size caused by static preparation method mentioned previously.
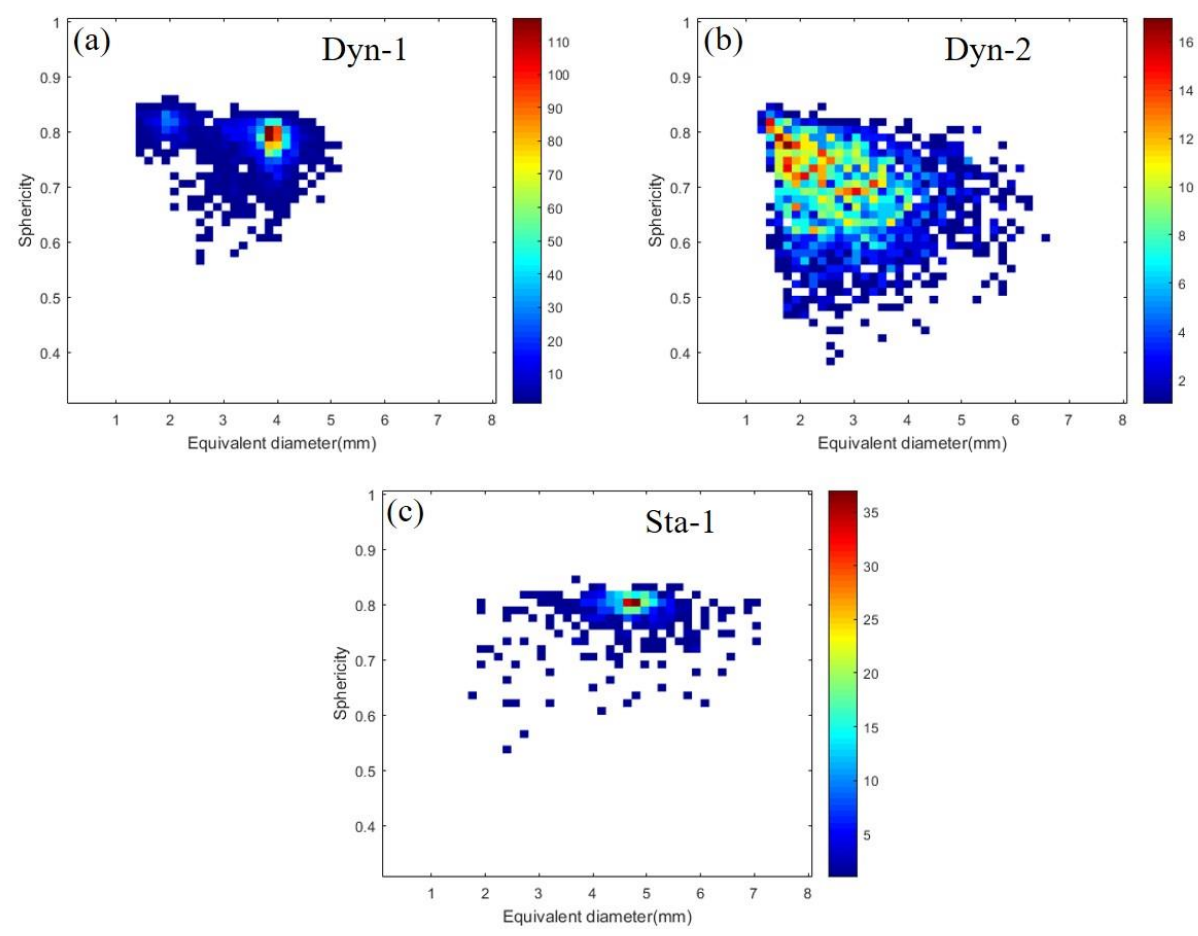

Fig. 7. Distributions of equivalent diameter and sphericity of cells in the three aluminum foams with a porosity around $85 \%$

\subsection{Analysis of cell deformation by in-situ compressive test of aluminum foam}

In order to study the deformation mechanism of the aluminum foam prepared by the dynamic gas injection method, a representative aluminum foam with a dimension of $8 \mathrm{~mm} \times 8 \mathrm{~mm} \times 10$ $\mathrm{mm}$ was compressed assisted by in-situ observation through X-ray tomography. After obtaining the $3 \mathrm{D}$ cell structure of the foam sample by X-ray tomography, the equivalent parameter of every splitted cell in the foam sample could be obtained by home-made plugins in Fiji software. Fig. 8(a) shows the frequency of cell size distribution in the foam sample, and most cell diameters are concentrated in $1 \sim 1.4 \mathrm{~mm}$. The average cell diameter is $1.19 \mathrm{~mm}$, so the cell size of the 
aluminum foam is relatively uniform. The overall porosity of the sample calculated by the tomography result is $70.9 \%$. In order to analyze the porosity uniformity in the foam, the 3D volume is divided into a number of $8 \mu \mathrm{m}$ thick (a voxel) slices along $x, y$ and $z$ directions, and Fig. 8(b) shows the calculated porosity of each slice along the three directions. It can be seen that the porosity of each slice in each direction is almost between $66 \% \sim 74 \%$. Therefore, pores are distributed relatively evenly throughout the foam sample. When there are few structural defects in the aluminum foam, the mechanical properties of small-size and large-size samples are similar [45]. The uniform cell size and porosity distributions indicate that there are few structural defects in the aluminum foam for in-situ compression. So the mechanical performance of the small size foam $(8 \mathrm{~mm} \times 8 \mathrm{~mm} \times 10 \mathrm{~mm})$ could represent the performance of bulk foam samples.
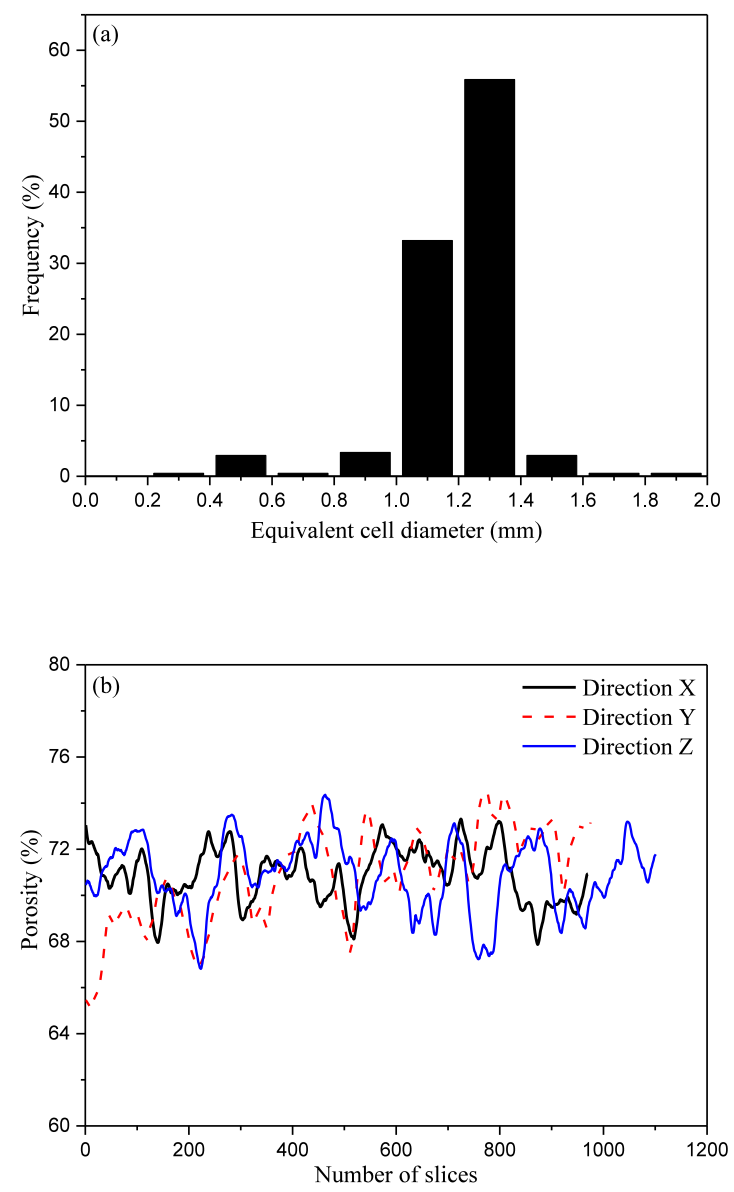

Fig. 8. (a) Distribution of the equivalent cell diameter of the foam sample for in-situ compression, (b) Porosity distribution of the foam sample along the three directions

Fig. 9 shows the quasi-static stress-strain curve of the aluminum foam during in-situ compression, and the densification strain calculated by the energy absorption efficiency-strain curve is also shown in Fig. 9. The three-stage compression feature is also observed in the stress-strain curve. There are also some fluctuations in the stress plateau stage. The amplitude of the fluctuations is gradually decreasing, which is mainly because broken cell walls will enter the interior of the non-deformed cells as the compression proceeds. Table 3 lists the calculated performance parameters of the aluminum foam according to Fig. 9. The plateau stress of the gas 
injection aluminum foam could reach $22 \mathrm{MPa}$ and the densification strain energy could reach 11 $\mathrm{MJ} / \mathrm{m}^{3}$ when the cell size is reduced to around $1 \mathrm{~mm}$ and sufficiently uniform. Compared to the best results in Fig. 2 and 3, it can be seen that the mechanical performance is nearly doubled. Therefore, reducing the cell size (usually the relative density will increase accordingly) and improving its uniformity are effective ways to improve the mechanical properties of an aluminum foam.

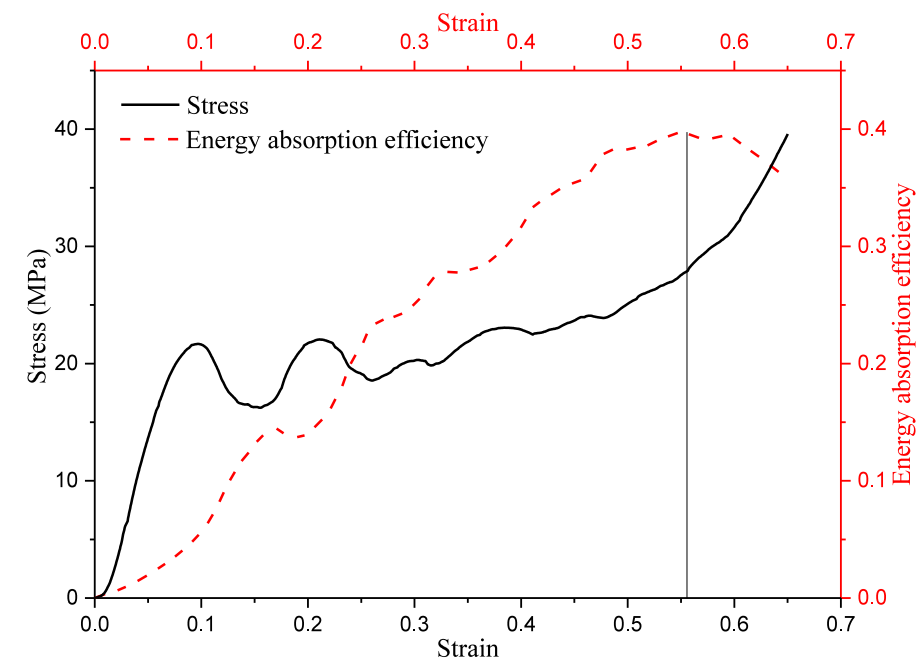

Fig. 9. Stress-strain curve of the aluminum foam during in-situ compression

Table 3 The performance parameters of the aluminum foam for in-situ compression

\begin{tabular}{lllll}
\hline Parameters & Values & & Parameters & Values \\
\cline { 1 - 2 } \cline { 5 - 6 } Porosity (\%) & 70.9 & & Densification strain (\%) & 55.6 \\
Average cell diameter (mm) & 1.19 & & Densification strain energy $\left(\mathrm{MJ} / \mathrm{m}^{3}\right)$ & 11.1 \\
First peak stress $(\mathrm{MPa})$ & 21.7 & & Plateau stress $(\mathrm{MPa})$ & 21.6 \\
\hline
\end{tabular}

In order to study the failure mechanism of the aluminum foam in cell level, a slice which belongs to the $x z$ plane in the middle of the $y$ direction in the coordinate system shown in Fig. 10 is selected, and the cell deformation process in this slice is shown in Fig. 11. Because the cell deformation may be affected by the surrounding cells, the deformation of internal cells which are more general were chosen for study. It can be found that there are mainly two failure forms of cell walls:

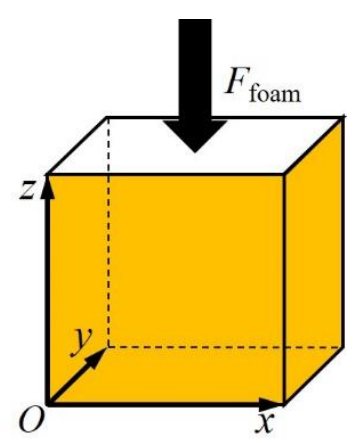

Fig. 10. The coordinate system used to analyze the morphology of a certain slice 


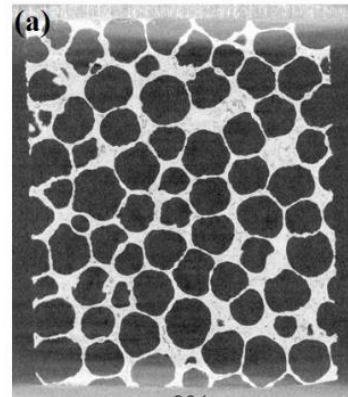

(e)

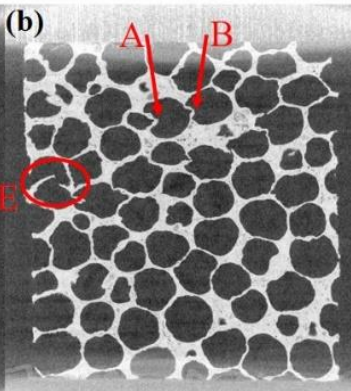

(f) (c)

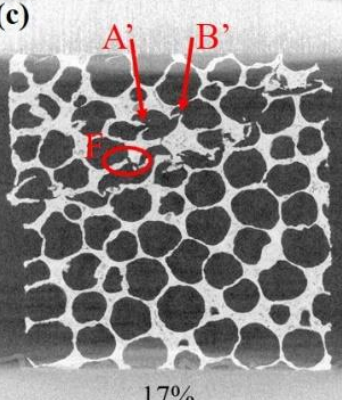

(g) (d)

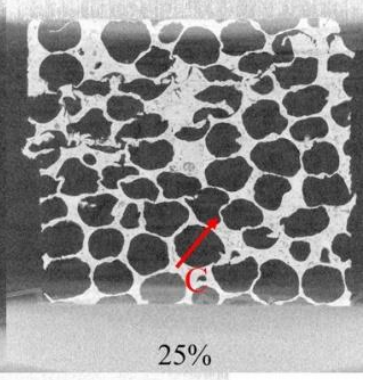

$25 \%$

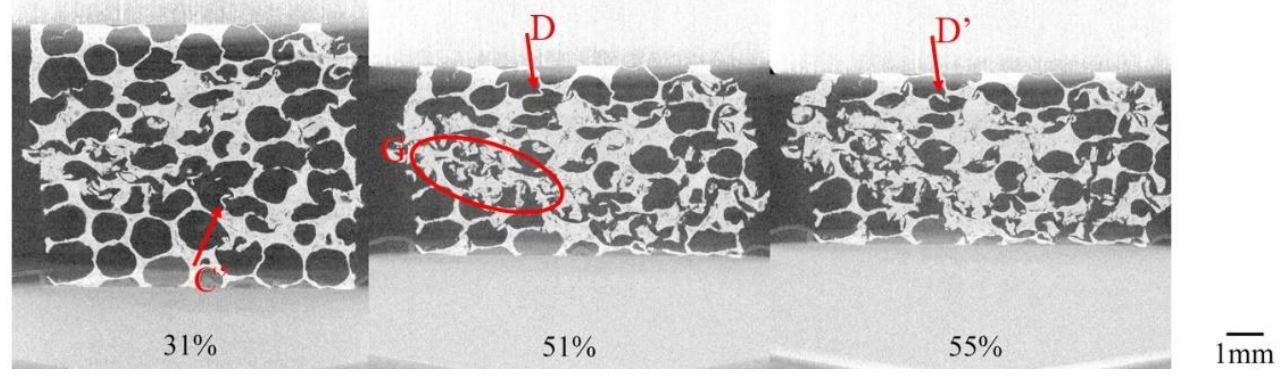

Fig. 11. The cell deformation process in the slice located in the middle of the $y$-direction

(1) The cell walls first appear buckled, then they fracture under the shear or tensile stress. A (or $\mathrm{B}), \mathrm{C}$ and $\mathrm{D}$ are typical cell walls failure in this form during the collapse of three layers of cells, respectively, and their morphologies after deformation are shown as A' (or B'), C' and D'. This failure is caused by pressure directly transmitted to the cell walls. Fig. 12 shows the deformation process of cell walls $\mathrm{A}$ and $\mathrm{B}$, the lengths of the walls are both around $0.8 \mathrm{~mm}$. Cell wall $\mathrm{A}$ is rather aligned compared to the compression direction and then first buckles under the compressive load, and then it is torn apart; Cell wall B first buckles, and then fractures under the shear stress.

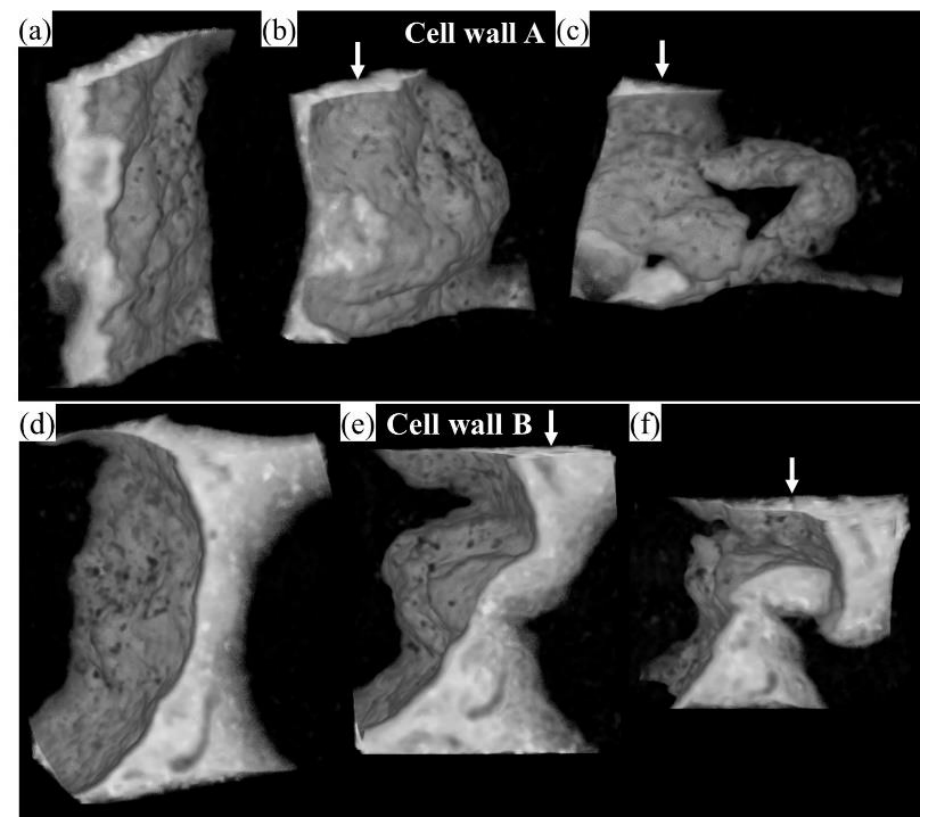

Fig. 12. The failure mode of the cell walls with buckles first and then fracture 
(2) The direct fracture of the cell walls. This failure is usually caused by the inconsistent deformation of cells on both sides of the cell wall, as described by cell walls E and F in Fig. 11. The cell walls fracture under the tensile or shear stress. Fig. 13 shows the deformation process of cell wall $\mathrm{E}$, the length of which is about $0.6 \mathrm{~mm}$. It can be seen that cell wall $\mathrm{E}$ directly fractures under the shear stress.

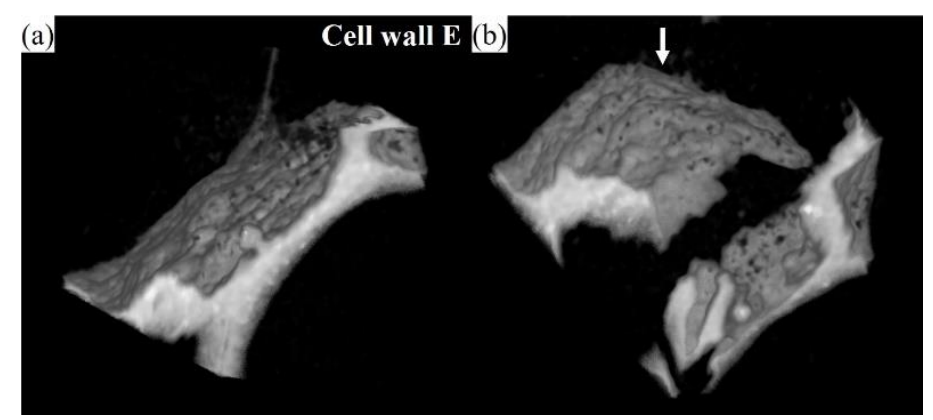

Fig. 13. The failure mode of the cell wall with direct fracture

The two main failure modes of the cell walls are relatively simple, which is also related to the brittleness of the gas injection aluminum foam. Failures of the cell walls could contribute to the energy absorption of aluminum foams. In addition, the friction between the cell walls after the cells are compacted also contributes to the energy absorption [35,36], as shown in the region $\mathrm{G}$ in Fig. 11.

\section{Conclusions}

1) The bulk aluminum foams prepared by the dynamic gas injection method with high-speed horizontal oscillation have the porosities of $75 \% \sim 95 \%$, and their plateau stress is in the range of 0.3-11 MPa. The plateau stress and densification strain energy both increase with the increase of relative density (namely the decreasing of porosity). There are some serrated waves in the plateau stage of stress-strain curves, which is mainly caused by the brittleness of aluminum foams prepared by gas injection method. The ceramic particles, oxide films, coarse eutectic silicon phase in the matrix, and the relatively thin normal cell wall contribute to the brittleness of the aluminum foam.

2) The dynamic gas injection method with high-speed horizontal oscillation could greatly reduce the cell size of aluminum foams and increase the relative density, and then the mechanical properties of aluminum foams can be improved. Moreover, due to the better cell wall performance and smaller cell size, the aluminum foam prepared by the dynamic gas injection method has better mechanical properties compared to that prepared by static method even for the same relative density. For aluminum foams with the same preparation process and the similar relative density, the more uniform cell size and sphericity distributions lead to higher mechanical properties of aluminum foams.

3) When the cell size of the aluminum foam prepared by the dynamic gas injection method is reduced to around $1 \mathrm{~mm}$ and relatively uniform, the plateau stress of the foam could reach up to $22 \mathrm{MPa}$, and the densification strain energy could reach $11 \mathrm{MJ} / \mathrm{m}^{3}$. The results of the in-situ compressive test show that there are two main failure modes for cell walls of gas injection aluminum foams: the fracture after plastic buckling of the cell walls and the direct fracture of the cell walls. 


\section{Acknowledgements}

This work is supported by the International Cooperation Project of Science and Technology Ministry of China (Grant no. 2013DFR50330). The authors would like to thank the Tsinghua Scholarship for Overseas Graduate Studies.

\section{References}

[1] J. Banhart, Light-Metal Foams-History of Innovation and Technological Challenges, Adv. Eng. Mater. 15 (2013) 82-111.

[2] J. Banhart, Manufacture, characterisation and application of cellular metals and metal foams, Prog. Mater. Sci. 46 (2001) 559-632.

[3] L.J. Gibson, M.F. Ashby, Cellular solids: structure and properties, Cambridge University Press, Cambridge New York, 1997.

[4] E. Andrews, W. Sanders, L.J. Gibson, Compressive and tensile behaviour of aluminum foams, Mater. Sci. Eng., A. 270 (1999) 113-124.

[5] W. Jang, W. Hsieh, C. Miao, Y. Yen, Microstructure and mechanical properties of ALPORAS closed-cell aluminium foam, Mater. Charact. 107 (2015) 228-238.

[6] M.I. Idris, T. Vodenitcharova, M. Hoffman, Mechanical behaviour and energy absorption of closed-cell aluminium foam panels in uniaxial compression, Mater. Sci. Eng., A. 517 (2009) $37-45$.

[7] J. Yuan, Y. Li, Effects of cell wall property on compressive performance of aluminum foams, Trans. Nonferrous Met. Soc. China. 25 (2015) 1619-1625.

[8] T. Mukai, T. Miyoshi, S. Nakano, H. Somekawa, K. Higashi, Compressive response of a closed-cell aluminum foam at high strain rate, Scr. Mater. 54 (2006) 533-537.

[9] R. Edwin Raj, V. Parameswaran, B.S.S. Daniel, Comparison of quasi-static and dynamic compression behavior of closed-cell aluminum foam, Mater. Sci. Eng., A. 526 (2009) 11-15.

[10] L. Lefebvre, J. Banhart, D.C. Dunand, Porous Metals and Metallic Foams: Current Status and Recent Developments, Adv. Eng. Mater. 10 (2008) 775-787.

[11] X. Chen, N. Wang, J. Yuan, Y. Li, H. Zhang, Y. Liu, Modeling of Macro-deformation Behavior of Thin-Walled Aluminum Foam by Gas Injection Method, J. Mater. Eng. Perform. 26 (2017) 3307-3318.

[12] T. Shi, X. Chen, Y. Cheng, Y. Li, Foaming Process and Properties of 6063 Aluminum Foams by Melt Foaming Method, Mater. Trans. 58 (2017) 243-248.

[13] T. Yu, Y. Li, J. Yuan, The influence of pure $\mathrm{Al}$ and hypoeutectic Al-Si alloy base materials on the cell structures of aluminum foams produced by gas injection foaming process, J. Funct. Mater. 19 (2015) 19041-19045.

[14] A.E. Markaki, T.W. Clyne, The effect of cell wall microstructure on the deformation and fracture of aluminium-based foams, Acta Mater. 49 (2001) 1677-1686.

[15] J. Kadkhodapour, S. Raeisi, Micro - macro investigation of deformation and failure in closed-cell aluminum foams, Comput. Mater. Sci. 83 (2014) 137-148.

[16] Y. Chen, R. Das, M. Battley, Effects of cell size and cell wall thickness variations on the strength of closed-cell foams, Int. J. Eng. Sci. 120 (2017) 220-240. 
[17] Y. Sugimura, J. Meyer, M.Y. He, H. Bart-Smith, J. Grenstedt, A.G. Evans, On the mechanical performance of closed cell Al alloy foams, Acta Mater. 45 (1997) 5245-5259.

[18] Y. Li, Comparison of aluminium foams produced by melt foaming and gas injection processes, Spec. Cast. Nonferrous Alloys. 31 (2011) 1097-1099.

[19] A.E. Simone, L.J. Gibson, Aluminum foams produced by liquid-state processes, Acta Mater. 46 (1998) 3109-3123.

[20] A. Elmoutaouakkil, L. Salvo, E. Maire, G. Peix, 2D and 3D characterization of metal foams using X-ray tomography, Adv. Eng. Mater. 4 (2002) 803-807.

[21] D. Leitlmeier, H.P. Degischer, H.J. Flankl, Development of a Foaming Process for Particulate Reinforced Aluminum Melts, Adv. Eng. Mater. 4 (2002) 735-740.

[22] I. Jin, L. D. Kenny, H. Sang, Method of producing lightweight foamed metal, USA Patent 4973358 (1990).

[23] Y. Zhou, Y. Li, J. Yuan, The stability of aluminum foams at accumulation and condensation stages in gas injection foaming process, Colloids Surf., A. 482 (2015) 468-476.

[24] X. Fan, X. Chen, X. Liu, Y. Li, Properties of aluminum foam prepared by gas injection method, Chin. J. of Nonferrous Met. (2011) 1320-1327.

[25] N. Babcsán, D. Leitlmeier, H.P. Degischer, Foamability of Particle Reinforced Aluminum Melt, Materialwiss. Werkstofftech. 34 (2003) 22-29.

[26] H. Sang, L.D. Kenny, I. Jin, Process for producing shaped slabs of particle stabilized foamed metal, USA Patent 5334236 (1994).

[27] N. Babcsán, S. Beke, P. Makk, P. Soki, G. Számel, H.P. Degischer, R. Mokso. ALUHAB - The superior aluminum foam., TMS (The Minerals, Metals \& Materials Society), (2012).

[28] F. García-Moreno, B. Siegel, K. Heim, A.J. Meagher, J. Banhart, Sub-mm sized bubbles injected into metallic melts, Colloids Surf., A. 473 (2015) 60-67.

[29] N. Wang, X. Chen, Y. Li, Z. Liu, Z. Zhao, Y. Cheng, Y. Liu, H. Zhang, The cell size reduction of aluminum foam with dynamic gas injection based on the improved foamable melt, Colloids Surf., A. 527 (2017) 123-131.

[30] H. Zhang, X. Chen, X. Fan, Y. Li, Compressive properties of aluminum foams by gas injection method, China Foundry. 9 (2012) 215-220.

[31] N. Babcsán, S. Beke, P. Makk, G. Szamel, C. Kadar, Pilot Production and Properties of ALUHAB Aluminium Foams, Procedia Mater. Sci. 4 (2014) 127-132.

[32] D. Wang, W. Xue, X. Meng, Z. Shi, Cell structure and compressive behavior of an aluminum foam, J. Mater. Sci. 40 (2005) 3475-3480.

[33] M.A. Kader, M.A. Islam, M. Saadatfar, P.J. Hazell, A.D. Brown, S. Ahmed, J.P. Escobedo, Macro and micro collapse mechanisms of closed-cell aluminium foams during quasi-static compression, Mater. Des. 118 (2017) 11-21.

[34] M.A. Islam, P.J. Hazell, J.P. Escobedo, M. Saadatfar. In-situ quasistatic compression and microstructural characterization of aluminium foams of different cell topology, Int. J. Aerosp. Mech. Eng. 8 (2014) 1285-1290.

[35] Y. Mu, G. Yao, L. Liang, H. Luo, G. Zu, Deformation mechanisms of closed-cell aluminum foam in compression, Scr. Mater. 63 (2010) 629-632.

[36] H. Song, Q. He, J. Xie, A. Tobota, Fracture mechanisms and size effects of brittle metallic foams: In situ compression tests inside SEM, Compos. Sci. Technol. 68 (2008) 2441-2450.

[37] I. Jeon, T. Asahina, K.J. Kang, S. Im, T.J. Lu, Finite element simulation of the plastic collapse of 
closed-cell aluminum foams with X-ray computed tomography, Mech. Mater. 42 (2010) 227-236.

[38] C. Petit, E. Maire, S. Meille, J. Adrien, Two-scale study of the fracture of an aluminum foam by X-ray tomography and finite element modeling, Mater. Des. 120 (2017) 117-127.

[39] N. Wang, X. Chen, Y. Li, Y. Liu, H. Zhang, X. Wang, Preparation and Compressive Performance of an A356 Matrix Syntactic Foam, Mater. Trans. (2018) M2018003.

[40] J.Y. Buffiere, E. Maire, J. Adrien, J.P. Masse, E. Boller, In Situ Experiments with X ray Tomography: an Attractive Tool for Experimental Mechanics, Exp. Mech. 50 (2010) 289-305.

[41] N. Wang, E. Maire, Y. Cheng, Y. Amani, Y. Li, J. Adrien, X. Chen, Comparison of aluminium foams prepared by different methods using X-ray tomography, Mater. Charact. 138 (2018) 296-307.

[42] N. Movahedi, E. Linul, L. Marsavina, The Temperature Effect on the Compressive Behavior of Closed-Cell Aluminum-Alloy Foams, J. Mater. Eng. Perform. 27 (2018) 99-108.

[43] K.Y.G. Mccullough, N.A. Fleck, M.F. Ashby. Uniaxial Stress-Strain Behaviour of Aluminium Alloy Foams. Acta Mater. 47 (1999) 2323-2330.

[44] J. Banhart, J. Baumeister, Deformation characteristics of metal foams, J. Mater. Sci. 33 (1998) 1431-1440.

[45] I. Jeon, T. Asahina, The effect of structural defects on the compressive behavior of closed-cell Al foam, Acta Mater. 53 (2005) 3415-3423. 